\title{
Conscious sedation in non comatose patients submitted to intra - arterial thrombolysis: our experience
}

\author{
Y Valzani ${ }^{1 *}$, A Marudi ${ }^{2}$, S Baroni ${ }^{2}$, A Zini ${ }^{2}$, S Vallone ${ }^{2}$, E Bertellini $^{2}$ \\ From ESICM LIVES 2015 \\ Berlin, Germany. 3-7 October 2015
}

\section{Introduction}

Recent studies have demonstrated that general anesthesia worsen outcome of patients affected by acute ischemic stroke (AIS) who underwent intra arterial thrombolysis [1]. General anesthesia (GA) guarantees adequate oxygenation and prevents pneumonia aspiration. On the other hand general anesthesia induces hypotension worsening brain injury. Futhermore it does not allow to verify early recovery of neurological deficits during the procedure.

Conscious sedation (CS) can represent a valid and reliable option in non comatose patients suffering from AIS and candidated to endovascular reperfusion procedure [2].

\section{Objectives}

To show our experience in CS during intra arterial reperfusion.

\section{Methods}

We collected data from patients affected by AIS who underwent intra arterial thrombolysis (pharmacological thrombolysis and mechanical thrombectomy) admitted in our hospital from January 2014 to December 2014 and the anesthesia type. We recorded demographics data, Glasgow Coma Scale score at admission and lenght hospital stay. Data were expressed as mean \pm standard deviation.

\section{Results}

59 affected by AIS were admitted to Our hospital and submitted to endovasculare recanalization procedure. Male to female ratio was 1:1, mean age $59 \pm 4$, mean Glasgow Coma Scale score (GCS) at the admission was $11 \pm 2$, mean duration of procedure was $58 \pm 16$ minutes.

${ }^{1}$ Universita degli Studi di Modena e Reggio Emilia, Modena, Italy Full list of author information is available at the end of the article
General anesthesia was performed in 12 patients and conscious sedation in 47 patients.

Patients were submitted to GA because of patients' anxiety or rapid worsening of neurological condition.

6 patients submitted to GA died in intensive care unit becasue of neurological complications.

Mean hospital lenght of stay was $8 \pm 4$ days for patients underwent CS.

Mean hospital lenght of stay was $18 \pm 7$ days for patients underwent GA.

\section{Conclusions}

CS can reduce lenght of stay in hospital and mortality of non comatose patients who undergo intra arterial reperfusion in comparison to general anesthesia [3]. Futher investigations are necessary to confirm our results.

\section{Authors' details}

${ }^{1}$ Universita degli Studi di Modena e Reggio Emilia, Modena, Italy. ${ }^{2}$ Nuovo Ospedale Civile Sant'Agostino Estense, Modena, Italy.

Published: 1 October 2015

References

1. John S, Thebo U, Gomes J, Saqqur M, Farag E, Xu J, Wisco D, Uchino K, Hussain MS: Intra-arterial therapy for acute ischemic stroke under general anesthesia versus monitoredanesthesia care. Cerebrovasc Dis 2014, 38(4):262-7.

2. Brinjikji W, Murad MH, Rabinstein AA, Cloft HJ, Lanzino G, Kallmes DF: Conscious Sedation versus General Anesthesia during Endovascular Acute Ischemic Stroke Treatment: A Systematic Review and MetaAnalysis. AJNR Am J Neuroradiol 2015, 36(3):525-9, Mari:

3. McDonald JS, Brinjikji W, Rabinstein AA, Cloft HJ, Lanzino G, Kallmes DF: Conscious sedation versus general anaesthesia during mechanical thrombectomy for stroke: a propensity score analysis. J Neurointer Surg 2014, 26-011373, Sep; pii: neurintsurg-2014.

doi:10.1186/2197-425X-3-S1-A990

Cite this article as: Valzani et al:: Conscious sedation in non comatose patients submitted to intra - arterial thrombolysis: our experience. Intensive Care Medicine Experimental 2015 3(Suppl 1):A990. (c) 2015 Valzani et al.; This is an Open Access article distributed under the terms of the Creative Commons Attribution License (http:// creativecommons.org/licenses/by/4.0), which permits unrestricted use, distribution, and reproduction in any medium, provided the original work is properly cited. 